Finally, unless substantial legislative and executive powers similar to those vested in the constituent units of a fullfledged federal system of government are devolved to the government of the Tamil majority state, the ethnic problem cannot be resolved to the satisfaction of both the Sinhalese and Tamil communities.

\section{Notes}

1. The cargo vessel owned by the LTTE was intercepted by the Indian Navy on January 13, 1993 and escorted towards the Indian coast. When the Indian Navy commandos attempted to board the vessel on January 16, 1993, Kittu and nine other senior military personnel committed suicide. See Tamil Times 8, no. 2 (February 15, 1993): 4-6 and 19 for the conflicting accounts that have been presented by the Indian government and the LTTE leadership on the circumstances that led to the interception, the exact location of the vessel when it was impounded, and the manner in which the LTTE personnel lost their lives.

2. Veluppillai Prabhakaran's interview with Mrs. Anandhi Sooriyapragasam was broadcast over the Tamil service of the BBC on March 2, 1993. An English translation of this interview was published in Tamil Times 8, no. 3 (March 15, 1993):4-5. In reply to a question of whether the LTTE leader will accept a federal system of government to resolve the ethnic conflict, Prabhakaran stated, "If a federal scheme that recognizes the territorial integrity of the Tamil homeland is put forward, we are ready to considerit. There are many forms of federal systems of government with varying degrees of powers that are devolved. We are prepared to consider a federal system which provides for sufficient autonomous powers that fulfills the political aspirations of the Tamil people."

3. see C.Manogaran, The Indo-SriLanka Accord of 29 July 1987, Round Table, 306, 1988, p. 198.

4. Census of Population and Housing (Population classification by Sex, Age, Religion, and Ethnic Groups by Towns for Urban Areas and AGA Divisions) Colombo, Government Press, 1981.

5. Padawi Sripura is the newly formed AGA division in the Trincomalee District. See Sri Lanka Survey Department, Map of New District Divisions (Colombo, 1987).

6. Some of the reasons advanced by Tamils for the need to maintain the North-East Province intact (merged) have been presented in C. Manogaran, Ethnic Conflict and Reconciliation in Sri Lenka (Honolulu: Hawaii Press, 1987), 179-80.

\title{
Mental Health Resilience of Refugees: The Case of Tamil Refugees
}

\author{
Megan Stuart Mills
}

What Fanon described as "The Pathology of Atmosphere" created by counterinsurgency in Algeria has been recreated over the last decade in SriLanka. Warfare involving guerrilla and antiguerrilla organizations does indeed present special threats to the mental health of combatants and civilians alike (Fanon 1961).

Canada's Tamil refugees, often hailing from Sri Lanka's now devastated northern and eastern provinces, bring with them many memories of state forces' manoeuvres designed to affect ordinary civilians. A key concept of counterinsurgency everywhere in the world continues to be found in the aim of destroying the popular power base of "terrorist" organizations. The nature of guerrilla activities dictates heavy reliance on the cooperation of ordinary people within districts of operation. Thus, those endeavouring to curb insurgent fish will focus strategically upon the waters in which the fish swim. The Tamil refugee's experience is also likely to be one of extreme apprehension due to the presence of sometimes volatile internecine struggles among insurgent factions pursuing different approaches to a secessionist goal of Tamil Eelam [see Bush in this issue]. Furthermore, some in the Ontario Tamil community will carry with them memories of the brutal sweeps of the Indian Army in Jaffna, who were ostensibly involved in peacekeeping operations. Violence, acute fear and everyday suffering represent a Sri Lankan Tamil experience not likely to be forgotten for several generations.

Sri Lanka's often appalling human rights record through the 1980 s translates into factors of strong importance within the Ontario Tamil community. Community leaders who assist refugees

Megan Stuart Mills is a Ph.D. candidate in the Department of Social and Political Thought at York University. consistently referred to a large number of male refugees under the age of thiry-five from directly affected areas in Sri Lanka. Sixty percent of this group are known to have undergone torture. When the whole Tamil refugee community in Canada was described, it was stressed that 90 percent of males and females of all ages have suffered extreme and longstanding fear, loss of family members and kin, plus loss of property and livelihood. The stresses of displacement, curtailed movement and lack of access to information have a profound effect on the refugees. It sometimes is not realized, by people unfamiliar with war-time conditions, that the Sri Lankan conflict carries on within a sea of propaganda. In such situations violence or threatened violence and rumours combine powerfully to create a "hall of mirrors" effect in which it is difficult to determine what is true or what is actually happening (Barnett 1988).

One Toronto psychiatrist involved in the treatment of refugee patients explained to me that, "one would have to be singular indeed to come away from such environments minus some eventual trouble or other". Nevertheless, it is important to understand that "many simply do." This fact became very plain over the course of research carried out through the summer months of 1992; it became obvious that Tamils, at least in the southern Ontario locale covered, are very resilient. In fact, this resilience came to characterize those within the community who endured the most terrifying experiences prior to leaving Sri Lanka.

In this way research undertaken to assess the extent of psychiatric illness among Tamil refugees quickly moved on to research that attempted to account for a widespread absence of mental illness. Matters of Tamil mental health began to fit well with material drawn from fields of cross-cultural psychology and particularly ethnopsychiatry. This sec- 
ond field boasts a great depth of work concerning South Asian peoples, both within their indigenousculture zone and abroad. Previous study of Tamil culture and religion and exposure to the Tamil areas of South India andSriLanka helped to piece together factors which I later felt Iought to have predicted. It remains true that South Asian questions tend to drive the neat-and-tidy thinking of occidental theorists to distraction. South Asian phenomena will continue to contrast and confound; despite the march of development and globalized everything.

Drawing a thumbnail sketch of Tamil refugees' resilience involves several factors, particularly issues of Tamilidentity. The sense of Tamilness within each refugee arriving in a country of asylum has proven stronger than the ravages of concerning mental resilience against war-time trauma. Rutter concludes that children in particular may be unaffected, given the buffering mechanisms of group membership and a strong spirit of group identity (Rutter 1985). Of course, both of these advantages are part and parcel of the Tamils' survival. Tamils abroad continue to live within elaborate networks of extended families, reciprocalrelationships and longstanding social or other group connections. It must be realized too, that group identity is predictably enhanced by conditions of adversity. That the Tamil condition is inseparably related to a firm ethnonationalist political agenda in the absence of less radical goals for a Tamil future can only be a galvanizing source of identity. Differences of old are forgot-

\section{Tamils are blessed with the identity and cohesion of a millennia. old classical culture understood better by some than others, but which is part of the awareness of all.}

counterinsurgency, including the terrifying military and "Psyops" techniques designed to wear down resistance, to disorient and politically paralyze. This resolve undoubtedly owes much to the social cohesiveness of South Asian peoples at large. Ethnic affiliation and connection with kin prevail as facts of life which have only been intensified by the experience of what can be considered a destructive anti-Tamil campaign. Family and kin remain knitted together also, in patterns possibly long gone from the Western industrialized world. Moreover, Tamils are blessed with the identity and cohesion of a millennia-old classical culture understood better by some than others, but which is part of the awareness of all. Whether dwelling in India or Sri Lanka - or for that matter, London, England, or Mississauga, Ontario-Tamil refugees are individual members of Tamilakam, the ideological and literary term for the collective Tamil cultural region (Stein 1977, 7-26).

An interesting comparison exists in Rutter's work of the past twenty years ten, shared traits and interests are obviously strengthened through the arrival of a clear political goal. It may even be necessary in the 1990s to learn to see world ethnonationalisms, including the Tamil Eelam movement, as equivalents of "ethnic religion" a phenomenon of powerful unifying ability (Smith 1990).

Matters of mental resilience that have to do with factors of Tamil identity by no means implies that all Tamils have supported or support the aims and methods of Tamil Eelamist paramilitaries. Indeed, many refugees are those who suffered at their hands. With regard to averting psychiatric consequences of trauma, and much to the envy of many a Westerner, the Tamil at least possesses an indelible, fully internalized sense of who he or she is.

A clarifying comparison is easily made with the Northern Irish case. A full two decades of study have culminated in themes accounting for the non-appearance of the "generation of psychopaths," once routinely said to be promised by the communal and state violence of the early 1970s. It now seems that Northern Irish children in disturbed areas do grow up faster, that individuals are tougher minded and generally very cautious in encounters with strangers. Nevertheless, Northern Irish children have been protected from major psychiatric trauma by closely knit families, a sense of ethnic identity, plus a reinforcing resolve that is the result of the shared experience of adversity (Curran and Greggs 1990).

In addition to the identity factor, Tamil resilience results from the more expressly South Asian. As a South Asian people, it is simply predictable that some advantage will stem from matters of the psyche which are religious. The integrally religious cultures of South Asia can be seen as both the fruit and the very foundations of a civilization pitted against sometimes trying challenges of survival. It is interesting that developments in Western theories of applied social science now show new appreciation of world views shaped by religious ideas and observances. According to a recent article, religious outlooks offer constructive philosophies, plus more holistic and accepting ideas of personhood, life and notably, the way to cope effectively with adversity (Andersonet al. 1991). Furthermore, religious world views are seen to encourage a sense of group responsibility and of group solutions to the challenges of living. Those North Americans who are prone to notions of religion as a set of rules or as a kind of psychological crutch will not easily understand Tamil culture in which religion, in different ways, permeates life. Most Tamil refugees in Ontario are Saivite-Hindus of the Saiva Siddhantin philosophies existent in Sri Lanka since the sixth century. Hinduism of this variety is noted for its open-minded style: the tradition encourages the individual to follow his or her own path to union with the divine while putting a strong emphasis on group involvement and service as the individual's earthly duty.

An estimated 25 percent of the Ontario Tamil population are Christians, mainly Roman Catholics. Typical of South Asia's propensity for religious synthesis, Saivite Hindu and Roman Catholic ideas have merged since the in-

Refuge, Vol. 13, No. 3 (June 1993) 
troduction of Catholicism in Sri Lanka by the Portuguese in the 1500 s. Many refugees hail from families of virtual Saivite Catholicism. I learned that since the Tamil diaspora of the early 1980s, the involvement of Tamils in Roman Catholic parishes and temple congregations in countries of asylum has tended to be high. It is most significant that there are few gaps between members of these religions: in fact, Tamil language or cultural classes will quite normally be taught in Canada by practising Roman Catholics; also, Tamils who possess a very Englishstyle education and culture may be known as quite orthodox Hindus. While religious life is an important component of Tamil culture and identity, its strains
A comparison is possible with the methods and aims of current Western psychotherapy-the psychotherapeutic process of the patient's dedication to the true nature of feelings and situations is familiar to many Tamils. While South Asia's ideal of acceptance has often been criticized by Westerners who regard it as fatalism, the reality is ironically different. A North American who is unable to accept a given situation or personality might be told by a South Asian that the heart of the matter is the person's unwillingness rather than inability to accept.

Nevertheless, the suffering undergone by Tamils in Sri Lanka particularly through the 1980 s can often be identified as extreme. In fact, the ordeals of indi-

\section{The growing literature of ethnopsychiatry suggests that diagnoses and treatments of disorder can be incorrectly identified.}

are merged within a larger historical ethnic identity. With regard to the psychiatric resilience of Tamil refugees, both religious traditions have fostered an unmistakably South Asian and Tamil outlook of great protective strength. Contact with Tamils in Ontario revealed that refugees have transplanted a mindset that stresses continual discernment of what is true, plus an ideal of accepting events that are not alterable. South Asia's philosophical cornerstone of the world as a great cosmological chaos within God's larger plan, early on encourages an awareness of the often unpleasant elements of life that cannot be changed. In contrast with the Westerner's typical interest in what should be or what ought to happen, Tamil thinking involves adherence to what is simply true. Balance and symmetry and purpose-the things that render life worth living - are promoted by devotions and observances in a family, community or a broader form of membership. In short, there is much to said for the determination of what is to be immediately and properly done in a situation as opposed to the parts of a situation which cannot be affected (Gangadaram and Selvanayagam 1992). vidual refugees prior to their arrival in Canada will often shock Canadians of more normative life experiences. Few Canadian-born people are likely to understand the variegated horrors of an air attack; very few will know the psychological imprint of having a family member taken into custody, or knowing that offspring were tortured while in custody. I was particularly impressed by a recurring and straightforward statement from several people interviewed: "others have gone through far worse." In many cases, the stresses of migration and resettlement will provide powerful distractions from their previous experiences in Sri Lanka. In keeping with other refugee populations in Canada, Tamils sometimes have longterm effects of the civil war even after adjusting to the demands of finding employment, housing and other immediate concerns. As emphasized elsewhere in this discussion, the fact that Tamils are proving mentally resilient does not imply a complete absence of psychiatric trauma. Most important with regard to the provision of better refugee health services, is the likelihood that occasional Tamils who seek psychiatric treatment will present strong chal- lenges related to their ethnicity. As two research psychologists once put it, South Asians "are different" (Good and Good 1986).

The growing literature of ethnopsychiatry suggests that diagnoses and treatments of disorder can be incorrectly identified. For instance, victims of war-time conditions, torture or other trauma are often diagnosed according to the late twentieth century's blanketing label of Post-Traumatic Stress Disorder. PTSD's symptoms are often discernible in patients after a short or sometimes very long interval following experienced trauma (Davidson 1991). Patients from South Asia however, are apt to have symptoms that are atypical within Western populations: anxious states are more common than depressive ones, and somatized or conversion reactions not regularly found inNorth American-born patients are frequent in South Asia and among South Asian expatriates (Csordas 1990; Steiner and Bansil 1989)

Metabolically, Tamil patients can be expected to respond a little differently to drugs administered by physicians. Antidepressants and tranquilizers given to relieve unpleasant symptoms en route to adjustment, will often show effects in comparatively low dosages (Keh-Ming et al. 1986; Qureshi 1988). It is to be hoped that mental health practitioners who assist Tamil patients will avail themselves of a body of findings that are emerging mostly from the United Kingdom's larger and longer established South Asian communities.

It is significant too that what occurs in the course of treatment will bear the imprint of patients' different ideas of mental health and trauma. Tamils arriving in Canada in the mid-1980s, who are more apt to come from less Westernized, Tamil-speaking backgrounds can be expected to present and respond differently. To summarize a host of cultural and acutely psychological factors to a great degree, the psychiatric disturbance in a South Asian patient will often be the instance of intrapsychic adjustment. The long "talking cure" of Western psychotherapy may not seem relevant or helpfuldue to the continuing phenomenon of a South Asian patient's experience of a 
short-term but acute psychiatric disturbance, which is the catharsis. Such an episode may be followed very shortly by complete adjustment and the departure of symptoms. All of this must seem very odd to an uninformed medical professional who anticipates long stages of gradual recovery (Jones 1976; Kakar 1984).

Furthermore, those hoping to help Tamil refugees must accept the likelihood of ongoing respect for traditional Tamil forms of naturopathic medicine. British communities of South Asians from various origins have indicated a prevailing respect for non-Western healing approaches. Sometimes these are used in conjunction with the Western medicine dispensed by the National Health; different types of therapy maybe sought depending on the ailment (Waqar 1991; Bhopal 1986).

In short, just as factors of Tamilness have proven equal to the trials of contemporary counterinsurgency in terms of protecting Tamils from widespread psychiatric disturbance, factors of their ethnicity must be taken seriously in better helping individuals who are traumatized. Moreover, a number of shortcomings in Canadian popular thinking must be taken into account; as suggested earlier, stresses placed upon refugees do not cease upon arrival in countries of asylum, nor with an apparently satisfactory resettlement. It is frequently overlooked that Tamil refugees often continue to contend with the stress of waiting for loved ones from Sri Lankan districts known to be dangerous. Few Canadian human service workers are likely to fully grasp the implications of the Sri Lankan state's increasingly aggressive antiTamil campaign. Ongoing awareness of hardship and suffering in Sri Lanka are not simply cancelled by the minister's permit or for that matter, the case worker (Beiser 1991).

At different times in the course of research, I wondered if the only hope for Sri Lanka might lie in what appears to be a widespread and largely cultural resilience.Dr.Hellman-Rajanayagam'snotes on her 199091 visit to Jaffna are probably still relevant-trips to villages she said possessed a "surreal quality." Despite falling bombs and the general mayhem of destruction, there was a good deal of squabbling over social niceties befitting a visitor (Hellman-Rajanayagam 1991).

Similarly, a Canadian photojournalist returning from Sri Lanka in late 1992 remarked that stereotypical Tamil traits of warmth and generosity seemed to have withstood the years since her last visit to Sri Lanka. A certain distinctly Tamil attitude prevailed even among families living in precarious conditions of displacement and economic uncertainty. Tamil identity, whether considered as a by-product of ethnonationalism or a typically Third World product of an age-old Tamil culture, offers its ideals of the proper approaches to even the sufferings of war. Adaptability as a part of resilience would seem to be proving as equal to the deprivation and bloodshed of late twentieth century counter-insurgency, as it has to all trials endured over centuries within the Tamil zone of India and Sri Lanka. $\mathbf{m}$

\section{References}

Anderson, Robert W. et al. 1991. "Prevention Theory and Action from the Religious Perspective." Prevention in Human Services 10: 9-27.

Barnett, Richard J. 1988. Low Intensity Warfare: Counter Insurgency, Pro Insurgency and AntiTerrorism in the Eighties. Edited by Michael Klare and Peter Kornbluh. New York: Pantheon.

Beiser, Morton. 1991. "The Mental Health of Refugees in Resettlement Countries." In Refugee Policy in Canada and the United States, edited by Howard Adelman, 425-42. Toronto: York Lanes Press.

Bhopal, R.S. 1986. "The Inter-relationship of Folk, Traditional and Western Medicine with an Asian Community in Britain." Social Science and Medicine 32: 99-105.

Csordas, Thomas J. 1990. "The Psychotherapy Analogy and Charismatic Healing." Psychotherapy 27.

- 1985. Medical and Sacred Realities Between Comparative Religion and Transcultural Psychiatry. Culture, Medicine and Society 9: 103-16.

Curran, P.S., and W. Greggs. 1990. "Psychiatric Aspects of Terrorist Violence in Northern Ireland, 1969-1986." The Medico-Legal Journal 58: 83-96:

Davidson, Jonathan. 1991. "Post Traumatic Stress Disorder in the Community-An Epidemiological Study." Psychological Medicine 21: 713-21.
Fanon, Franz. 1961. The Wretched of the Earth. Translated by Constance Farrington. New York: Grove Press.

Gangadaram, S., and Israel Selvanyagam. 1992. "The Communion of Saints: Christian and Tamil Saiva Perspectives." The HinduChristian Bulletin 5: 13-20.

Good, Byron and Mary Jane Good. 1986. "The Cultural Context of Diagnosis and Therapy-A View from Medical Anthropology." Mental Health and Practice in Minority Communities. Washington: National Institute of Mental Health.

Hellman-Rajanayagam, D. 1991. "Sri LankaA Current Perspective." Asian Affairs 22: 314-29.

Jones, W.T . 1976. "World Views and Asian Medical Systems-Some Suggestions for Further Research." In Asian Medical Systems, edited by C. Leslie. Berkeley: University of California Press.

Kakar, Sudhir. 1984. Shamans, Mystics and Doctors: a Psychological Inquiry into India and Its Healing Traditions. London: Unwin.

Keh-Ming, Lin et al. 1986. "Ethnicity and Psycho-Pharmacology." Culture and Medicine and Society 10: 151-65.

Qureshi, B. 1988. "How Ethnic Origins Complicate Drug Therapy." Geriatric Medicine 18: 61-63.

Rutter, M. 1985. "Resilience in the Face of Adversity: Protective Factors and Resistance to Mental Disorder. British Journal of Psychiatry 147: 598-611.

Smith, Anthony D. 1990. "The Supercession of Nationalism?" International Journal of Comparative Sociology 31: 1-31.

Stein, Burton. 1977. "Circulation and the Historical Geography of Tamil Country." Journal of Asian Studies 37: 7-26

Steiner, L., and R. K. Bansil. 1989. "Cultural Patterns the Family System in Asian Indians-Implications for Psychotherapy." Journal of Comparative Family Studies 20: 371-76.

Wagar, Ahmad. 1991. "The Maligned Healerthe Hakim and Western Medicine." New Community 18: 521-36.

"History can be constructed to reinforce ethnicidentities at odds with those defined as the other. Alternatively, historical understanding can be the basis of fostering harmonious relations with other groups."

- Professor Howard Adelman (in this issue). 